\title{
ACESSO DIGITAL: $O$ DIREITO À INFORMAÇÃO NA ÁREA DA SAÚDE VERSUS A PROPRIEDADE INTELECTUAL DA INFORMAÇÃO TECNOLÓGICA ${ }^{12}$
}

\author{
Rosana Evangelista \\ Vanda de Fátima Fulgêncio de Oliveira \\ Sandra Lúcia Pareira \\ Valdinéa Sonia Petinari
}

\section{Resumo:}

A Engenharia Clínica ou Hospitalar tem a responsabilidade de gerenciar todo o ciclo de vida das tecnologias de saúde, o que inclui o processo de especificação, aquisição, instalação, testes de aceitação, treinamento, manutenção corretiva e preventiva e todos os assuntos referentes aos equipamentos. A documentação necessária para atender a estes objetivos está armazenada na Central de Referência em Equipamentos Biomédicos no Centro de Engenharia Biomédica da Universidade Estadual de Campinas (UNICAMP). O objetivo deste trabalho é analisar a viabilização da implantação da digitalização dos documentos, que hoje estão apenas na forma impressa, restringindo o acesso. Os profissionais técnicos e instituições remotas serão beneficiados com esta ação. Os direitos autorais, a infraestrutura de software, o desenvolvimento das bibliotecas digitais, e as características das publicações e do público usuário são discutidos. Como resultado identificamos, qualificamos e agrupamos os usuários da documentação. Este levantamento ofereceu subsídios para tomada de decisão a respeito da melhor forma de atendimento deste cliente virtual.

\section{Palavras-Chave:}

Gestão da informação na área da saúde; Informação em engenharia biomédica; Direitos autorais; Biblioteca digital; Usuário virtual

\section{DIGITAL ACCESS: THE RIGHT TO INFORMATION IN HEALTH CARE VERSUS INTELECTUAL PROPERTY OF THE TECHNOLOGICAL INFORMATION}

\begin{abstract}
:
Clinical Engineering is responsible for the management for the whole life cycle of medical equipment and related technology. This includes the specification, acquisition, installation, acceptance tests, training, preventive and corrective maintenance of medical equipment. The necessary documentation to attend these activities is stored in the Reference Center on Medical Equipment of the Center for Biomedical Engineering of the State University of Campinas. This paper analyses the possibility of digitizing all documents to allow their access via digital means, as they are available only in print form. The technical professionals and institutions would certainly be benefited with this action. In this paper we discuss amongst other topics, copyright, software needed, digital library development, document and user and publication characteristics. As a result we have identified, qualified and grouped all users of the documentation. We were then able to decide on the best way to allow the access to the digitized documents by the virtual clients. The main problem we have found is the need for the manufacturer's agreement with this procedure, this point is 1 not solved yet.
\end{abstract}

\section{Keywords:}

Health care Information management; Information on biomedical engineering; Copyright; Digital library; Virtual user

\footnotetext{
${ }^{1}$ Este artigo é resultado do trabalho do Grupo de Estudos em Informação na Área da Saúde.

${ }^{2}$ Artigo apresentado no Evento IFLA PRÉ CONFERÊNCIA M\&M: o cliente virtual: um novo paradigma para melhorar o relacionamento entre clientes e serviços de informação e bibliotecas, 2004, São Paulo.
} 


\section{INTRODUÇÃO}

O quadro sanitário brasileiro deve ser analisado levando-se em conta a perspectiva de um Brasil de dimensões continentais e marcado por imensas desigualdades entre os diferentes extratos sociais, tanto no que diz respeito à renda, às condições ambientais, às dificuldades ao acesso a direitos tidos como elementares quanto à saúde, à educação, à moradia e ao transporte.

Os últimos 30 anos no Brasil foram caracterizados por um desenvolvimento industrial acelerado ao nível urbano e por grandes investimentos agrícolas, mas ainda ressentimonos de investimentos em saneamento básico, pois é crescente o contingente de pessoas inseridas na linha de pobreza urbana, onde os reflexos das suspensões de programas preventivos e de controle de endemias já se fazem notar através do ressurgimento de doenças tidas como erradicadas de nosso meio, como: dengue, tuberculose e outras que vêm alertar para dois importantes fatores nesse quadro: 1) Urbanização não planejada e massiva como forma de disseminação de doenças infecto-contagiosas, anteriormente circunscritas às zonas rurais; 2) A urbanização como fator de surgimento de maior número de doenças crônico-degenerativas, afetando todas as faixas etárias; a esse quadro somaríamos o envelhecimento da população.

Portanto, ainda que se possa visualizar um maior índice de acesso da população aos serviços de saúde, também se verifica a dificuldade dos hospitais do setor público em manterem sua rede funcionando e na capacidade de absorção dessa nova parcela da população agora mais idosa, sem deixar de atender seus clientes tradicionais que são as mulheres e as crianças, significando assim um alargamento das suas competências (CASTELAR; IWERSEN, 1995).

O desafio da incorporação de novas tecnologias perante esse quadro deve levar em consideração fatores como a estreita relação custo-efetividade dos serviços a serem oferecidos.

O incremento tecnológico a que diversas áreas do conhecimento humano têm sido submetidas atinge de forma intensa a área da saúde, no que tange aos equipamentos médico-hospitalares. Os estabelecimentos de saúde são impelidos a incorporarem em suas 
estruturas equipamentos cada vez mais sofisticados, que proporcionam a realização de diagnósticos e tratamentos mais precisos e complexos do ponto de vista médico e mais humanos do ponto de vista do paciente.

Porém, juntamente com essa evolução há que se adotar metodologias que garantam o nível de qualidade dos serviços de assistência à saúde da população com o intuito de melhor gerir os expressivos aportes de recursos despendidos com a aquisição dessas tecnologias e sua posterior manutenção.

A modernização tecnológica, por si só, tem elevado a complexidade do funcionamento dos serviços, e da administração do mesmo. Este desenvolvimento leva, freqüentemente, o hospital a rever sua forma de gerência, visto que confrontos são quase que inevitáveis, envolvendo equipamentos médicos e seus níveis de desempenho, alto custo de manutenção, elevação do índice de reparos e a sua rápida obsolescência tecnológica.

Quando os recursos e a infra-estrutura são limitados o perigo do uso não apropriado da tecnologia e até mesmo a sua disponibilidade quando necessária fica claramente comprometida, ou seja, há tecnologia disponível incorporada ao serviço, mas nem sempre confiável.

Centros de informação, como a CREB (Central de Referência em Equipamentos Biomédicos) que vamos analisar neste trabalho, tem papel fundamental no controle das informações que podem auxiliar o quadro acima exposto.

Neste contexto a informação é fundamental para atender os fatores acima mencionados. Na prática da Ciência da Informação é intrínseca a relação com as outras disciplinas ou áreas do saber, ou seja, é necessário que o profissional da informação busque entender a dinâmica de cada área e a partir desta compreensão desenvolver metodologias próprias para a gestão das informações geradas.

Este artigo tem como objetivo discutir as questões sobre direitos autorais, infra-estrutura de software, bibliotecas digitais, caracterização das publicações e do público usuário, bem como estabelecer critérios para a análise de cada documento, segundo sua especificidade, definindo quais são passíveis de digitalização, ou seja, aqueles que 
atendam às exigências da lei de direitos autorais e se enquadram na infra-estrutura computacional existente, dando subsídios ao projeto de implantação da Biblioteca Digital do CEB (Centro de Engenharia Biomédica) para disponibilização on-line dos documentos que acompanham ou deveriam acompanhar os equipamentos médicos.

Desta forma, propomos o compartilhamento da experiência do CEB na gestão de documentos em tecnologia biomédica, um tema relevante para a prática do profissional da informação.

\section{Gestão de Tecnologias de Saúde e Informação Técnica}

O CEB foi criado em 5 de outubro de 1982, pela portaria GR 133, para congregar esforços de ensino e pesquisa em Engenharia Biomédica que existiam até então diluídos, em vários departamentos da Universidade, sendo seu objetivo atuar de modo paralelo e integrado na pesquisa básica e no desenvolvimento tecnológico, bem como na formação de recursos humanos e no apoio à área da saúde da UNICAMP.

A Engenharia Biomédica é uma especialidade relativamente recente e tem prestado importante contribuição às ciências biomédicas e à tecnologia aplicada a problemas médicos. Podemos destacar como objeto de suas sub-áreas as seguintes atividades:

- Bioengenharia - (Estudo de fenômenos e sistemas biológicos com técnicas e métodos quantitativos) nesta atividade o interesse fundamental é o estudo do sistema biológico para que técnicas e métodos das ciências exatas venham a ser utilizados com sucesso na melhoria do entendimento da biologia.

- Engenharia Médica - desenvolve dispositivos, métodos e equipamentos para finalidades diagnósticas, terapêuticas, de ensino e pesquisa nas áreas de saúde e biologia, estando nesta sub-área o desenvolvimento de instrumentação e processamento de sinais e dados, ensaios de produção de equipamentos médicos e de pesquisa.

- Engenharia de Reabilitação - derivada da antiga área de desenvolvimento de instrumentação médica, as atividades nesta área estão direcionadas ao apoio (na forma de desenvolvimento de métodos, técnicas e instrumentos) ao deficiente físico. 
- Física Médica atua em Medicina Nuclear, Proteção Radiológica, Radiodiagnóstico e Radioterapia entre outras práticas.

- Engenharia Clínica ou Hospitalar tem a responsabilidade de gerenciar todo o ciclo de vida das tecnologias de saúde, o que inclui o processo especificação, aquisição, instalação, testes de aceitação, treinamento, manutenção corretiva e preventiva e todos os assuntos referentes aos equipamentos.

A Área de Engenharia Clínica do CEB é responsável, entre outras atividades, por providenciar a manutenção corretiva e preventiva dos equipamentos de finalidades odonto-médico-hospitalares das Unidades de Saúde da UNICAMP conforme podemos visualizar na tabela abaixo, de acordo com as solicitações de serviços atendidos no ano de 2003.

TABELA 1 - Quantidade de Ordens de Serviços (OS) realizadas no ano de 2003.

\begin{tabular}{|l|l|}
\hline Nome do grupo & Total de OS \\
\hline Diagnóstico & 1538 \\
\hline Imagem & 704 \\
\hline Laboratório & 1972 \\
\hline Mecânica & 4012 \\
\hline Total & 8226 \\
\hline
\end{tabular}

Fonte: Sistema de Gerenciamento de Ordem de Serviço do CEB

A manutenção dos equipamentos médico-hospitalares é dividida por grupo, isto é, cada um dos grupos da Engenharia Clínica é responsável por alguns tipos de equipamentos, sendo uns mais complexos que outros. Portanto, o total de OS concluídas por um determinado grupo não implica que ele tenha produzido mais. A produção, nesse caso, não é medida pelo número de OS concluídas e sim pela complexidade da manutenção.

Preocupa-se também esta área, com a implantação de programas para gerenciamento de tecnologia médica, no que tange ao desenvolvimento de protocolos para avaliação pré e pós-aquisição de equipamentos, programas de manutenção, otimização dos recursos materiais e humanos, treinamento de operadores e técnicos em manutenção bem como atuar no desenvolvimento de plano para prevenção de riscos e para detecção, registro e investigação de acidentes envolvendo equipamentos médico-hospitalares. 
A Agência Nacional de Vigilância Sanitária (ANVISA), através da Gerência Geral de Tecnologia de Produtos para Saúde, publicou o documento: Boas Práticas de Aquisição de Equipamentos Médico-Hospitalares ${ }^{3}$ que tem como objetivo assegurar que os equipamentos médico-hospitalares adquiridos pelas instituições: 1) sejam adequados ao uso pretendido; 2) sejam compreendidos por seus operadores; 3) estejam em condições seguras de uso; 4) atendam as normas e regulamentos técnicos que dispõem sobre a segurança, desempenho, instalação e uso destes equipamentos.

A geração de uma documentação técnica, descrita nos procedimentos operacionais da instituição, é dividida da seguinte forma: a) Registros do recebimento; b) Controle da documentação; c) Livro (diário) ou cartão de registros; d) Registros dos treinamentos e prescreve ainda que:

\begin{abstract}
a instituição deve realizar a guarda e controle de toda documentação referente ao recebimento, instalação e aceitação do equipamento, incluindo sua documentação técnica (manuais de operação e manuais de serviço) e atualizações efetuadas nesta documentação, devendo ainda divulgar nas unidades competentes as informações nelas contidas (ANVISA).
\end{abstract}

O documento apresenta algumas conceituações, das quais destacamos as que são de interesse específico deste trabalho:

- Manual de Operação: Conjunto de instruções, em língua portuguesa, necessárias e suficientes para orientar o usuário de equipamento médicohospitalar em seu uso correto e seguro.

- Manual de Serviço: Conjunto de informações técnicas necessárias e suficientes para a prestação de serviços de manutenção de equipamento médico-hospitalar, incluindo:

1. Esquemas eletrônicos, mecânicos e pneumáticos.

2. Procedimentos de manutenção preventiva e corretiva.

3. Procedimentos de calibração.

4. Relação das ferramentas e equipamentos necessários para a manutenção e para calibração.

5. Lista de partes e peças de reposição com os respectivos códigos de identificação.

\footnotetext{
${ }^{3}$ ANVISA, GGTPS, UTVIG. Boas práticas de aquisição de equipamentos médico-hospitalares. Disponível em : http://www.anvisa.gov.br/produtosaude/auto/boas.htm. Acesso em 16/04/2004.
} 
O documento apresenta - entre as diretrizes do edital de licitação - que o fornecedor, vencedor da licitação, deverá fornecer à instituição todas as informações técnicas em português, necessárias e suficientes para a operação correta e segura do equipamento (manual de operação) repetindo a mesma prescrição nas diretrizes do contrato com o fornecedor.

Conforme Calil (2000), o processo de aquisição deve considerar que a documentação técnica se torna imprescindível para que a Engenharia Clínica possa resolver defeitos que o equipamento apresente. Segundo o autor a documentação técnica deve ser entendida como: manual de serviço; manual de operação; esquemas mecânicos, esquemas eletrônicos, esquemas pneumáticos, procedimentos de calibração, lista de equipamentos de calibração, procedimentos de manutenção preventiva e lista de peças com maior freqüência de reposição e seus códigos respectivos.

Esta preocupação no processo de aquisição se justifica porque:

nem todos os equipamentos existentes no hospital possuem documentação técnica que auxilie sua manutenção. Enquanto alguns fabricantes se dispõem a entregar essa documentação gratuitamente, outros somente as vendem. Entretanto, nem todos os fabricantes estão dispostos a fornecer a documentação, tendo em vista que favorecem seus representantes técnicos na região (CALIL; TEIXEIRA, 1998, p. 25).

Dessa forma, os autores sugerem que, tão logo o grupo de manutenção seja implantado, o seu responsável deva visitar os vários serviços clínicos com a finalidade de reunir toda a documentação relativa aos equipamentos do hospital, inclusive os manuais de operação existentes, na tentativa de identificar a documentação faltante e buscar providenciá-la junto ao fabricante ou a outros hospitais que possuam o mesmo tipo de equipamento.

Ainda, de acordo Calil e Teixeira, (1998) outra preocupação no suporte às atividades de Engenharia Biomédica é a aquisição de publicações especializadas como: periódicos, manuais de manutenção, livros técnicos e livros sobre sistemas de gerenciamento em manutenção e sobre os princípios de funcionamento de alguns equipamentos médicohospitalares, para a atualização da equipe de profissionais e para a preparação de cursos e treinamentos, sendo importante também a existência de fontes de informações sobre os lançamentos de equipamentos médico-hospitalares nacionais e internacionais, locais de aquisição de peças de reposição, dispositivos de infra-estrutura predial e sensores 
médicos, servindo como fonte de informação para o caso de especificações técnicas de novas aquisições bem como para discutir com o corpo clínico sobre os recursos de cada equipamento.

\section{Propriedade Intelectual da Informação Tecnológica e a Democratização da Informação.}

Ao tentarmos discutir sobre propriedade intelectual da informação tecnológica a questão do registro tecnológico, protegido pelas patentes, parece interferir na busca por uma solução que atenda a necessidade social desta informação.

O retorno dos custos de desenvolvimento da tecnologia e a busca do lucro por parte das empresas proprietárias transformam em ilegais todas as iniciativas de democratização da informação que pretendem atender ao aspecto social, principalmente quando se verifica a dependência que a área da saúde tem deste tipo de informação, já que alguns equipamentos representam condições vitais aos pacientes que deles necessitam.

Sabe-se que, no setor industrial, a prática da concorrência significa o movimento principal entre os mercados, porém para se manterem ativas e lucrativas algumas empresas buscam o acesso a informações sigilosas de outras para que possam aplicá-las em seu produto e ter condições de entrar e/ou de se manter no mercado, muitas vezes sacrificando a existência das demais.

É uma situação que o capitalismo incentiva uma vez que a própria sociedade é movida pela questão financeira fazendo com que a informação tenha um caráter econômico.

Além da informação ser considerada uma mercadoria, esta também é um recurso social, pois a sua criação independe do número de pessoas que vão utilizá-la, não se desgasta pelo uso, pois é um bem intangível (CHEVERIE, 2002).

Tal afirmação poderia ser empregada para justificar a disseminação de toda a informação, porém para poder ter acesso a ela o usuário acaba pagando os custos da criação desta informação que são mais altos do que a de reprodução. Este elevado custo de criação é 
protegido pela lei de direitos autorais para que possa agregar valor à obra dos autores e também afastar os concorrentes (CHEVERIE, 2002).

Cheverie (2002) faz uma interessante discussão entre economia baseada em informação, desenvolvimento tecnológico e reserva de direitos de autor; esses assuntos são discutidos e analisados na tentativa de elucidar a importância/responsabilidade das bibliotecas com o domínio público da informação e essas implicações em época de copyright à medida que agregam valor à informação que protegem; descreve ainda o caráter econômico da informação que remonta da criação da lei de direitos autorais, lei que procura prover o retorno financeiro para o autor do custo empregado na produção da informação. A lei também assegura que, após o término de validade da lei, a informação ficará em domínio público. Porém, a rede de computadores tem acelerado o processo de circulação dessa informação e conseqüentemente a violação do direito (CHEVERIE, 2002). Isto também é exemplificado por Fernández-Molina (2003) quando descreve a possibilidade de acesso às obras digitais quase instantaneamente em qualquer lugar e em qualquer momento.

A missão das bibliotecas tem sido, ao longo do tempo, preservar e tornar pública a informação que é gerada na sociedade. Quando esta missão é aplicada em ambientes educacionais, é visível que a informação produzida, quando utilizada pelos estudantes e pesquisadores, resulta na criação de novos conhecimentos gerando novos bens públicos.

Desta forma, as bibliotecas mantêm um papel importante em assegurar ao público o direito de acesso às informações, balanceando a rigidez da lei de direitos autorais (CHEVERIE, 2002) e revendo inclusive suas práticas sociais relativas ao uso da informação (MICHEL, 1997).

A questão da propriedade intelectual da informação tecnológica não deve ser confundida neste caso específico com o registro de pesquisas tecnológicas por meio de escritórios de patentes. Este artigo se destina à compreensão do tipo de material que é armazenado na CREB (Central de Referência em Equipamentos Biomédicos do Centro de Engenharia Biomédica da UNICAMP). Quando adquiridos, todos os equipamentos destinados à área da saúde da Universidade devem ser acompanhados de informação técnica que auxilie o profissional de manutenção destes equipamentos a compreender como funciona 
determinada tecnologia, e como consertar o equipamento, como se pode verificar na sessão anterior.

A Lei 9610 de 1998 que regulamenta o direito autoral no Brasil prevê que são obras intelectuais protegidas as criações do espírito, expressas por qualquer meio ou fixadas em qualquer suporte tangível ou intangível, conhecido ou que se invente no futuro (MARTINS FILHO, 1998). A documentação a que nos referimos e que devem acompanhar os equipamentos, se enquadram nesta lei uma vez que, além de representar o registro intelectual de informações a respeito dos equipamentos, esbarra na propriedade tecnológica e a questão do mercado de concorrentes conforme discutimos anteriormente.

Esta proteção legal se justifica perante os argumentos que já vimos até aqui e, portanto, é urgente que soluções surjam para que os Profissionais da Informação possam cumprir as exigências da sociedade. Fernández-Molina (2003) atesta que existem atualmente três soluções a serem empregadas neste caso: a legislativa, a tecnológica e a contratual. O autor espera que exista a possibilidade de se propor e concretizar modificações na Lei de Direitos Autorais e assim entende que a solução por meio legislativo possa trazer melhorias ao acesso.

Para nosso estudo compreendemos que as demais soluções propostas pelo autor acima (tecnológica e contratual), possam ser aplicadas neste caso específico.

A solução tecnológica significa o desenvolvimento de programas que monitorem o uso e a quantidade de acessos dos materiais digitalizados. A solução contratual deverá ser uma das principais ações propostas por este projeto, pois, pretende-se que os produtores da informação que desejamos disponibilizar eletronicamente, forneçam, por meio de contrato com a Universidade, o direito de darmos o acesso eletrônico para uma comunidade controlada através da solução tecnológica.

Iniciativas que tentam criar mecanismos de filtragem das informações em rede podem se tornar a solução para a questão da ausência de territorialidade na Internet, questão essa impossível de ser resolvida já que não existe dimensão geográfica para que as leis possam ser aplicadas de acordo com os territórios aos quais os infratores são submetidos dependendo do local onde cometeram a infração (GUEIROS JUNIOR, 2004). 
Ao utilizarmos a literatura como instrumento de orientação para o bom atendimento de nosso usuário virtual, as publicações fazem a descrição da Lei que já conhecemos e atestam que na Internet a regra também se aplica, porém o controle é mais difícil, uma vez que qualquer pessoa em qualquer parte do mundo pode disponibilizar informações até mesmo aquelas protegidas. Não se tem ainda plena certeza de como agir nestes casos, situação tal que pode atrasar ou prejudicar as iniciativas de utilização desta ferramenta para levar a informação a quem realmente necessita, principalmente como é o caso da área da saúde.

\section{Biblioteca na Rede Eletrônica}

O movimento que ocorreu com a criação das redes eletrônicas, impulsionou o profissional da informação na transformação do seu trabalho. Interessante notar que existiram fases nas quais ainda tentava-se compreender os benefícios e aplicabilidade desta ferramenta, e passou-se do auto-reconhecimento do profissional dentro deste novo enfoque até a quebra de paradigmas conforme descreve Pereira (1995) quando atesta que as funções de uma biblioteca tradicional passam por uma modificação de visão na qual é “evidente um deslocamento da ênfase no acervo, na coleção, para o acesso e a distribuição dos recursos informacionais" "4.

A autora acima procura responder em seu trabalho se esta Biblioteca Virtual poderá ser uma realidade, questão que podemos hoje responder facilmente bastando, para tanto, buscar na rede. Já naquela época, o usuário/cliente, apesar de não ser citado nesta passagem que transcrevemos, fica em evidência quando os profissionais procuram oferecer seus esforços para que a informação chegue até ele com esta ferramenta.

Em 1997, Drabenstott e Burman publicaram um trabalho de revisão com o objetivo de esgotar os aspectos envolvidos na Biblioteca do Futuro, assim como a chamaram, dentre tantas outras colocações, descreveram que os três atores envolvidos em todo o processo eram: os autores das publicações, os editores e os bibliotecários, atestando que entre os

\footnotetext{
${ }^{4}$ Nesta discussão procuramos autores que estudaram o acesso à informação remotamente não distinguindo as definições conceituais entre virtual, digital ou eletrônico, mas sim compreendendo que todas elas existem virtualmente e são acessadas remotamente.
} 
três deveria haver certa sintonia para que o acesso fosse integralizado pensando sempre no usuário final da informação.

Procurando descrever a missão deste espaço virtual as autoras descrevem que "necessário se faz formular políticas que visem à cooperação para tornar o acesso cada vez mais aberto e levado aos locais mais longínquos, tendo como base o uso de novas tecnologias sob comando de componentes humanos". Parece que, provavelmente, na época em que foi escrito, havia uma discussão sobre o desaparecimento do elemento humano nas novas mudanças e por isso nos dois trabalhos estes fatores são destacados reafirmando a necessidade do fator humano.

Também em 1997 foi publicado o documento "Orientações estratégicas para a implementação de bibliotecas virtuais no Brasil" desenvolvido pelo Grupo de Trabalho sobre Bibliotecas Virtuais do Comitê Gestor da Internet-Brasil (1997), neste documento, como uma das mais importantes orientações, descreve que as bibliotecas brasileiras podem vir a cumprir um papel fundamental na participação do Brasil na Internet primeiro em "virtude de sua condição de detentoras de importantes fontes de informação organizadas do país e, em segundo lugar, por sua vocação institucional de intermediação entre seu entorno e as fontes de informação, independentemente de sua localização". Entre as diversas recomendações deste trabalho está a "Organização de fontes de informação eletrônica e sua disponibilização" na qual esclarece que a Biblioteca pode promover a organização e disponibilização de suas próprias fontes de informação, dando acesso remoto aos usuários.

Cunha (1999) já mais recentemente faz uma leitura do momento e atesta que a evolução das tecnologias trouxe agilidade e confiabilidade no processo nesta época na qual as bibliotecas passavam pela automação de serviços partindo rapidamente para "virtualização" de tarefas, sempre preocupado, contudo, com o acesso remoto à informação.

Notamos facilmente que a tecnologia da informação está procurando atender as preocupações dos trabalhos acima citados e estamos em uma época em que os profissionais poderão, aliando suas habilidades à tecnologia, transformar seu ambiente físico em um ambiente sem paredes no qual a comunidade poderá acessar remotamente. 


\section{Software Livre e as Bibliotecas na Rede Eletrônica}

Já discutimos até o momento a questão dos direitos autorais e uma parcela do processo histórico no discurso dos pesquisadores que relataram a evolução da "virtualização" das bibliotecas. Optamos por dar esta ordem aos assuntos, pois parece-nos que a tecnologia de informação vem trazer subsídios para que os direitos autorais sejam respeitados e a dimensão democrática da Biblioteca Virtual/Digital seja contemplada adequadamente.

No mundo globalizado não existem mais países isolados. Embora a globalização não signifique uma homogeneização da sociedade, as diferenças e desigualdades existem e até mesmo são acentuadas, produzindo uma nova linguagem, um novo paradigma.

Junto à globalização vem o movimento de liberação dos códigos utilizados na construção dos grandes sistemas de informação/comunicação. Para estes, surge o Software Livre, assim como são chamados os sistemas que têm seu código-fonte aberto. São sistemas gerenciados por licenças pré-fornecidas por seus fornecedores, mas que se adequam ao ambiente e não ao contrário como acontece com a maioria dos sistemas comerciais.

Esta nova realidade é definida por Modesto (2003) como uma "alforria para as bibliotecas" o quê "não é sinônimo de facilidade de uso ou de gratuidade, mas de liberdade de uso".

Foi desenvolvido por pesquisadores ${ }^{5}$ da UNICAMP (Universidade Estadual de Campinas) um sistema do tipo Software Livre que já vem sendo utilizado dentro da própria Universidade e parece atender ao proposto neste artigo.

O sistema Nou-Rau foi originalmente desenvolvido para possibilitar a criação de repositórios digitais, mantidos por voluntários através da Internet. Os textos previamente aceitos para inserção estão sujeitos a uma indexação automática que localiza o termo pesquisado em qualquer parte do documento, contabilizando a quantidade de acessos ao mesmo tempo que identifica o usuário, podendo ser configurado de acordo com a intenção da biblioteca.

\footnotetext{
${ }^{5}$ Mais informações podem ser acessadas no endereço: http://www.rau-tu.unicamp.br/nou-rau/ 
Este acesso controlado que o sistema viabiliza, pode atender a questão do direito autoral, pois identifica o usuário que está solicitando, o qual pode ser contatado posteriormente caso seja feito uso indevido, como a comercialização da informação disponibilizada, que infrinja a Lei de Direitos Autorais.

Acreditamos que dessa forma um grande obstáculo pode ser vencido e as bibliotecas poderão, enfim, cumprir a missão de democratização do conhecimento.

Para Dennis (2001, p. 157), uma biblioteca digital deve incluir cinco componentes a serem contemplados para sua formação, sendo os quatro primeiros relacionados a infraestrutura de software e hardware tanto da biblioteca quanto do usuário final. Enfatizamos o último item, que relata que a criação e a conversão de dados é realizada pela biblioteca quando ela transforma a coleção local em acervo digital, sendo este o nosso enfoque.

Os documentos que estão armazenados no CEB poderão atender remotamente os Engenheiros do CEB e ainda democratizar este acesso aos Hospitais para que possam proceder à manutenção em seus equipamentos.

Conforme os dados levantados neste trabalho, alguns dos manuais existentes na CREB são referentes a equipamentos que não existem mais ou que estão com sua fabricação encerrada. Espera-se que, nestes casos, possamos digitalizá-los e disponibilizar seu conteúdo no Sistema Nou-Rau devidamente configurado para atender todas as questões anteriormente levantadas.

\section{Gestão da Informação na Central de Referência em Equipamentos Biomédicos}

Atendendo as necessidades de gestão da documentação técnica dos equipamentos foi criada na UNICAMP em 1985 a Central de Referência em Equipamentos Biomédicos (CREB) tendo como objetivo organizar as documentações técnicas.

Para que compreendêssemos melhor a existência do CEB e a importância da CREB realizamos entrevistas com alguns dos pesquisadores/docentes os quais participaram do projeto de implantação da CREB. 
Em relato pessoal, o professor Calil $(2004)^{6}$, pontua que o projeto da CREB teve inicio com o professor Wang Binseng ${ }^{7}$, pois havia um grande projeto de pesquisa junto com a OPS (Organização Pan-americana de Saúde) e dentro desta interação, houve um acordo no qual a OPS encaminharia a documentação técnica de equipamentos mais antigos ao CEB para juntar-se à documentação de alguns equipamentos já existentes na Universidade.

Bassani $(2004)^{8}$ relata que na época estava ocorrendo desperdício de equipamentos, devido a falta de documentação técnica para manutenção. Ainda, segundo Calil (2004), o projeto foi pensado como uma Central que atenderia ao Brasil e também países da América do Sul. Bassani (2004) complementa que a documentação seria compartilhada com outros grupos de Engenharia Hospitalar no Brasil.

O projeto surgiu no contexto de formação do Hospital das Clínicas e com um modelo de Engenharia Clínica que foi importado dos EUA na época, ou seja, seria criada uma Central com a documentação técnica original e os médicos ficariam com as cópias dos manuais de operação, o que iria garantir o controle e o acesso à documentação para manutenção, conforme nos relatou Calil (2004).

Além destes documentos o acervo também é composto por obras de referência, normas técnicas, literatura comercial, teses/dissertações, periódicos e multimeios atendendo a demanda de suporte às atividades de Engenharia Biomédica. A este acervo que era muito específico foram acrescentadas doações de alguns pesquisadores, vindos de viagens do exterior, e aos poucos pequenos acervos pessoais foram reunidos e formaram a atual coleção.

Classificamos a comunidade atendida pela CREB em três categorias: usuários internos técnicos, usuários internos acadêmicos e usuários externos ao CEB.

\footnotetext{
${ }^{6}$ Saide Jorge Calil, doutor em Medical Electronics. University of London, foi Diretor do CEB no período de 19871994.

${ }^{7}$ Wang Binseng, doutor em Ciências em Engenharia Bio-Elétrica pelo MIT, Fundador do CEB, atuando na gestão de 1982 - 1986.

${ }^{8}$ José Wilson Magalhães Bassani, doutor em Engenharia Elétrica pela UNICAMP, atual Diretor do CEB.
} 
A primeira categoria é formada pela equipe de engenheiros/técnicos de manutenção, totalizando 27; a categoria de usuários internos acadêmicos é formada pelos usuários cadastrados na CREB, os quais fazem parte da comunidade da universidade (alunos de graduação, pós-graduação, iniciação científica, especiais e docentes da universidade em geral) que totalizam 208 usuários com acesso parcial, pois podem consultar a documentação técnica apenas através de consulta local.

A Tabela abaixo quantifica e qualifica a primeira categoria:

TABELA 2 - Quantidade de usuários da Área de Engenharia Clínica do CEB

\begin{tabular}{|c|c|}
\hline Nome do grupo & $\begin{array}{l}\text { Quantidade } \\
\text { de usuários }\end{array}$ \\
\hline $\begin{array}{l}\text { Diagnóstico } \\
1 \text { Engenheiro; } \\
4 \text { Técnicos; } \\
1 \text { Estagiário. }\end{array}$ & 06 \\
\hline $\begin{array}{l}\text { Imagem } \\
1 \text { Engenheiro; } \\
3 \text { Técnicos; } \\
1 \text { Estagiário. }\end{array}$ & 05 \\
\hline $\begin{array}{l}\text { Laboratório } \\
1 \text { Engenheiro; } \\
6 \text { Técnicos; } \\
1 \text { Estagiário. }\end{array}$ & 08 \\
\hline $\begin{array}{l}\text { Mecânica } \\
1 \text { Engenheiro; } \\
6 \text { Técnicos; } \\
1 \text { Estagiário. }\end{array}$ & 08 \\
\hline $\begin{array}{r}\text { Total } \\
\text { ante } \cdot \text { Cadastro do Sis }\end{array}$ & 27 \\
\hline
\end{tabular}

A Tabela 2 mostra a quantidade de usuários internos técnicos (27) que podem retirar os manuais da CREB para fins de manutenção junto aos equipamentos da Universidade.

A disponibilização do acervo em formato eletrônico irá otimizar a efetivação das solicitações de manutenção corretiva e preventiva encaminhadas a estes profissionais (da Área de Engenharia Clínica) conforme foi verificado na Tabela 1 (Quantidade de Ordem de Serviço (OS) realizadas no ano de 2003) que atingiu um total de 8226. 
O segmento de usuários externos é formado pelas instituições hospitalares existentes nos vários estados brasileiros e em alguns países da América Latina que possuem equipamentos médico-hospitalares e são atualmente usuários potenciais, pois já foram atendidos no passado e hoje não podem mais solicitar documentação à CREB devido às restrições da Lei de Direitos Autorais.

TABELA 3 - Quantidade de Instituições Cadastradas na CREB

\begin{tabular}{|l|c|}
\hline \multicolumn{1}{|c}{ Localidade } & Quantidade \\
\hline Amazonas & 01 \\
\hline Bahia & 06 \\
\hline Ceará & 01 \\
\hline Distrito Federal & 08 \\
\hline Goiás & 01 \\
\hline Minas Gerais & 21 \\
\hline Mato Grosso & 02 \\
\hline Paraíba & 01 \\
\hline Pernambuco & 03 \\
\hline Paraná & 09 \\
\hline Rio de Janeiro & 34 \\
\hline Rio Grande do & 02 \\
Norte & \\
\hline Rio Grande do Sul & 12 \\
\hline Rondônia & 02 \\
\hline Santa Catarina & 05 \\
\hline Sergipe & 01 \\
\hline São Paulo & 123 \\
\hline Argentina & 07 \\
\hline Bolívia & 01 \\
\hline Colômbia & 01 \\
\hline Costa Rica & 01 \\
\hline Cuba & 01 \\
\hline Equador & 02 \\
\hline Guatemala & 01 \\
\hline México & 02 \\
\hline Peru & 01 \\
\hline Suriname & 01 \\
\hline Uruguai & 01 \\
\hline Total & \\
\hline
\end{tabular}

Fonte: Cadastro do Sistema de Informação da CREB

Essa última tabela apresenta a quantidade de instituições cadastradas junto à CREB, as quais têm interesse no acervo de manuais de equipamentos médicos para fins de manutenção nos seus equipamentos. 
Comparando as tabelas 2 e 3 observamos que existem muitos usuários em potencial que necessitam utilizar o acervo, mas que devido às restrições da Lei de Direitos Autorais nenhum usuário externo pode utilizar o acervo por meio de solicitação de documentação para efetivação da manutenção em seus equipamentos.

É importante ressaltar que estes usuários eram atendidos regularmente e ocorreu a interrupção do atendimento em respeito à Lei de Direitos Autorais.

O efetivo atendimento a estes usuários parece contribuir para o cumprimento social que a CREB tem condição de realizar, uma vez que estes usuários externos são instituições que trabalham com a saúde e necessitam disponibilizar os equipamentos em perfeito funcionamento. Se os estudos sobre a proteção intelectual progredirem positivamente, estes usuários terão o acesso garantido.

A informação na área da saúde, em nossa opinião, deve ser de livre acesso, pois o indivíduo que se beneficia dos recursos técnicos ou os profissionais médicos compreendem que estão recebendo um importante apoio e, provavelmente, não irão infringir a essência da lei, que na verdade quer proteger a produção intelectual do autor e não correndo o risco de ser plagiado com a obtenção de lucro com esta ação.

Para que esta relação entre os usuários e o acervo pudesse ser estabelecida e melhor compreendida houve a necessidade de se verificar a consistência da base de dados na qual toda a documentação técnica da CREB está registrada.

Para tanto foi necessário um inventário geral do acervo além do contato com a equipe de engenheiros e equipe de informática que em alguns casos foi de essencial apoio em definir a forma mais adequada de controle destes dados.

Este trabalho foi realizado em aproximadamente $30 \%$ do acervo somente após a conclusão deste levantamento poderemos responder a algumas questões como:

- quais e quantos documentos contêm a declaração do fabricante explicitando a proibição de reprodução protegendo os direitos autorais? 
- qual a quantidade de equipamentos com fabricação encerrada ou empresas não mais existentes?

- quantos equipamentos existem na Universidade para os quais a CREB não possui documentação técnica?

- qual o total de manuais da CREB para os quais não mais existem os equipamentos operantes?

Estas questões puderam ser elaboradas devido ao aprofundamento do estudo do acervo em andamento.

O número total de documentos é de aproximadamente 4 mil exemplares. Ao "filtrarmos" do Banco de Dados da CREB, os fabricantes, equipamentos e modelos obtivemos um resultado de 2879, ou seja, nesta seleção excluímos aqueles que apresentaram duplicação. A tabela 4 apresenta o resultado desta pesquisa.

TABELA 4 - Caracterização do acervo segundo a propriedade intelectual protegida

\begin{tabular}{c|c|c} 
Quantidade & Protegida & Não protegida \\
2879 & 394 & 2485
\end{tabular}

Fonte: Cadastro do Sistema de Informação da CREB

Conforme podemos ver na tabela 4, este total está dividido em 2 categorias, aqueles que possuem a expressão escrita de proibição de cópias (394), ou seja, possui um documento do fabricante, onde o mesmo solicita sigilo das informações constantes no manual, estando restrito somente para fins de manutenção dos equipamentos da UNICAMP; e aqueles que não possuem esta expressão (2485).

Outro importante ponto que está sendo identificado com o inventário é a quantidade de manuais para cada especialidade da Área de Engenharia Clínica do CEB que atende a Universidade, conforme a tabela abaixo: 
TABELA 5 - Quantidade de manuais por área

\begin{tabular}{|l|c|}
\hline Nome do grupo & Total \\
\hline Diagnóstico & 132 \\
\hline Imagem & 82 \\
\hline Laboratório & 163 \\
\hline Mecânica & 33 \\
\hline Outros $\quad 373$ \\
\hline \multicolumn{1}{|c|}{ Total } & 783 \\
\hline
\end{tabular}

Fonte: Cadastro do Sistema de Informação da CREB

Até o momento, atualizamos $18,79 \%$ da base de dados de manuais, porém 373 manuais não foram identificados no cadastro de equipamentos médicos do $\mathrm{CEB}$, ou seja, não puderam ainda ser agrupados em nenhuma categoria. Tal situação poderá futuramente ser respondida mediante duas hipóteses: 1) Existência de manuais que foram doados pela OPS para a UNICAMP para fazer parte da coleção, embora a UNICAMP nunca tenha possuído os equipamento; 2) Existência de manuais que foram adquiridos por doação de pesquisadores.

Para que possamos decidir quais manuais deverão passar pelo processo de digitalização e futura disponibilização on-line, estamos classificando o acervo em uma tabela de temporalidade segundo a teoria da arquivologia, que identifica três estágios de vida do documento:

- arquivos correntes: conjuntos de documentos em curso ou de uso freqüente;

- arquivos intermediários: conjuntos de documentos procedentes de arquivos correntes e que aguardam sua destinação final;

- arquivos permanentes: conjunto de documentos que são preservados, respeitando a destinação estabelecida em decorrência de seu valor probatório e informativo.

Os dados quantificados estão no quadro abaixo:

QUADRO 1 - Classificação dos Manuais

\begin{tabular}{|l|c|c|c|c|}
\hline Nome do grupo & Corrente & $\begin{array}{c}\text { Interme } \\
\text { diário }\end{array}$ & $\begin{array}{c}\text { Perm } \\
\text { nente }\end{array}$ & $\begin{array}{c}\text { Total } \\
\text { Parcial }\end{array}$ \\
\hline Diagnóstico & 116 & 3 & 13 & 132 \\
\hline Imagem & 76 & 1 & 5 & 82 \\
\hline Laboratório & 152 & 1 & 10 & 163 \\
\hline Mecânica & 33 & 0 & 0 & 33 \\
\hline Total & 377 & 5 & 28 & 410 \\
\hline
\end{tabular}


Devido ao já exposto anteriormente, 373 manuais não puderam ser agrupados nesta classificação, por isso o total aqui é de 410 manuais. Estes manuais conferem com os equipamentos que constam na listagem que foi gerada a partir da base de dados do CEB de equipamentos médico-hospitalares nos quais o CEB presta manutenção.

Dentre estes 410 manuais verificou-se que 5 estão agrupados no nível INTERMEDIÁRIO o qual corresponde ao status do equipamento desativado, porém não baixado. Tal status se refere aos equipamentos que o CEB recomendou desativação devido alguns problemas, tais como: custo do conserto não ser mais viável; por não haver mais peças de reposição disponíveis no mercado; por não atender as normas de segurança, entre outras possibilidades.

Como PERMANENTE podemos verificar um total de 28 manuais de equipamentos que foram desativados e já baixados do parque tecnológico da universidade.

A maioria dos manuais, ou seja, 377, pertencem ao nível CORRENTE, pois os equipamentos continuam funcionando adequadamente.

Interessante notar neste levantamento que os níveis INTERMEDIÁRIO $\mathrm{E}$ PERMANENTE, apesar de a Universidade não os utilizar mais efetivamente, este material poderia ser o primeiro lote a ser digitalizado. Isto permitiria que fosse armazenado em outro ambiente dando lugar aos novos manuais que venham a integrar o acervo. Esta digitalização atenderá a demanda do público externo que possivelmente ainda utiliza estes equipamentos.

Acreditamos que o processo de digitalização destes manuais possa ser melhor gerenciado uma vez que, com o passar dos anos de fabricação, provavelmente seja mais fácil a possível negociação com a empresa para que forneça uma declaração autorizando a digitalização e disponibilização destas documentações técnicas.

A digitalização do restante da documentação pode representar mais implicações devido a Lei de Direitos Autorais atrelada a Patente da Informação Tecnológica, porém nosso propósito é ir além destas questões de trabalhar com a informação passível de ser um bem 
público, além de atender este cliente virtual que no nosso caso específico são instituições de saúde.

\section{Propostas de Compartilhamento, Visibilidade e Democratização da Informação}

A gestão de unidades de informação é uma tarefa complexa que implica em tomadas de decisões com o poder de interferir no cotidiano dos indivíduos. Trabalhando com a área da saúde esta questão fica mais clara conforme discutimos neste trabalho.

Existe um ganho real quando utilizamos as tecnologias para diminuir a distância que existe entre o cliente e as unidades de informação.

Acreditamos que a CREB tem no seu acervo tecnológico, parcela significativa do conhecimento humano caracterizando-se como um bem público.

Entendemos que a "informação só tem sentido quando integrada a algum contexto. A informação por si só se constitui em um dado incompleto, é o indivíduo que lhe atribui sentido a partir de suas experiências passadas e interesse futuro" (FERREIRA, p. 1997). Dar visibilidade ao acervo de manuais, classificados como permanente e intermediário, significa oferecer aos usuários o potencial desta informação que está arquivada sem que o equipamento exista na Universidade.

Esperamos que as 251 instituições agrupadas como usuários externos, possam de alguma forma dar sentido a este acervo, se constituindo em um cliente virtual. Esta situação já pode ser gerenciada pelas tecnologias que estão surgindo no âmbito de controle e identificação de acesso virtual a custos baixos ou quase inexistentes.

O trabalho de inventário do acervo tem sido de fundamental relevância para o diagnóstico da situação atual e, a partir destes levantamentos, pretendemos traçar estratégias futuras da gestão, visando o compartilhamento, a visibilidade e a democratização da informação para aproximar o usuário deste acervo.

Quando o profissional da informação se propõe atingir os objetivos acima, acaba cumprindo uma de suas funções para a qual também é preparado, ou seja, o 
desenvolvimento de coleções, que encontra-se inserido no fazer biblioteconômico como instrumental capaz de apreender as necessidades, anseios e mudanças do fluxo informacional da comunidade usuária do serviço de informação.

A citação a seguir de Vergueiro (1989, grifo nosso) sumariza esta importante função:

\begin{abstract}
Trata-se de deixar clara a filosofia a nortear o trabalho bibliotecário no que diz respeito à coleção. Mais exatamente, trata-se de tornar público, expressamente, o relacionamento entre o desenvolvimento da coleção e os objetivos da instituição a que esta coleção dever servir, tanto por causa da necessidade de um guia prático na seleção diária de itens, como devido ao fato de ser tal documento uma peça-chave para o planejamento em larga escala. Além do mais, poderíamos dizer que o processo mesmo de elaboração desta política tem uma função pedagógica, digamos assim, à medida que propicia ao bibliotecário a oportunidade de auto-avaliação e reflexão sobre sua prática de desenvolvimento da coleção. Acrescenta-se também, que apenas a existência de tal documento pode garantir, pelo menos no limite do possível, uma coleção consistente e um crescimento balanceado dos recursos informacionais da biblioteca. [...] É ela que irá prover uma descrição do estado geral da coleção, apontar método de trabalho para consecução dos objetivos e funcionar como elemento de argumentação do bibliotecário, dando-lhe subsídios para discussão com autoridades superiores, tanto para a obtenção de novas aquisições como para recusa de imposições estapafúrdias.
\end{abstract}

Essa discussão compromete tanto profissionais da informação quanto à equipe gestora, conforme verificamos na citação acima. Por isso recorremos mais uma vez às entrevistas realizadas para que obtivéssemos informações e as expectativas para o futuro.

Há uma expectativa dos especialistas em Engenharia Biomédica que a CREB se torne um Centro de Referência em Informação de Engenharia Biomédica como "nucleador" e disseminador para o Brasil e América do Sul da informação armazenada (BASSANI, 2004; CALIL, 2004). Essa expectativa está atrelada ao desenvolvimento adequado desta coleção.

Devemos considerar que a missão da CREB é híbrida, tendo de um lado o foco na Engenharia Clínica visando a gestão de tecnologias de saúde vinculada ao Complexo Hospitalar - com um conjunto de competências relacionado a órgãos reguladores e fóruns específicos de discussão (ANVISA, MS, OMS, OPS) da área da saúde - e de outro lado, o foco acadêmico da Engenharia Biomédica organizando e disseminando informação científica para uso acadêmico.

Com essa orientação surge a necessidade de conciliar as práticas hoje vigentes com respaldos de uma Política de Desenvolvimento de Coleções, “ou seja: a política irá funcionar como diretriz para as decisões dos bibliotecários em relação à seleção do 
material a ser incorporado ao acervo e à própria administração dos recursos informacionais" (VERGUEIRO 1989).

Este trabalho, ao identificar, qualificar e agrupar os usuários da informação da CREB, oferece subsídios para as tomadas de decisões a respeito de quem é, e qual a melhor maneira de atingir seu público alvo. O relacionamento entre clientes e serviços de informação deve estar contextualizado dentro dos novos paradigmas da sociedade atual.

Recomendamos a continuidade do trabalho desta pesquisa com foco nas questões jurídicas relacionadas aos direitos autorais, elaboração de um documento de política de desenvolvimento de coleções e de projetos de infra-estrutura financeira para a viabilização da Biblioteca Digital do CEB.

\section{REFERÊNCIAS BIBLIOGRÁFICAS}

ANTUNES, Elizabeth; et al. A engenharia clínica como estratégia na gestão hospitalar. In: . Cooperação Brasil - França. Éditions Scientifiques ACODESS, 2002. cap. 4, p.

45-67. Disponível em: <http://www.anvisa.gov.br/tecnovigilancia/capitulo4.pdf> Acesso em: 16 abr. 2004.

ANTUNES, Elizabeth; et al. Gestão da tecnologia biomédica: tecnovigilância e engenharia clínica. Paris: ACODESS, 2002. 210 p.

ANVISA; GGTPS; UTVIG.[s.d.] Boas práticas de aquisição de equipamentos médicohospitalares. Disponível em: <http://www.anvisa.gov.br/produtosaude/auto/boas.htm> Acesso em: 16 abr. 2004.

BASSANI, José Wilson Magalhães. [Entrevista] 01/04/2004 às 8h45min. 2004.

CALIL, Saide Jorge. Critérios para aquisição de equipamentos médico-hospitalares. In: CONGRESSO BRASILEIRO DE ENGENHARIA BIOMÉDICA, 17., 2000, Florianópolis. Anais... Florianópolis: UFSC, 2000, p. 38-45.

CALIL, Saide Jorge. [Entrevista] 14/04/2004 às 11 horas. 2004

CALIL, Saide Jorge. Análise do setor de saúde no Brasil na área de equipamentos médicohospitalares. In: NEGRI, Barjas; DI GIOVANNI, Geraldo (Org.). Brasil: radiografia da saúde. Campinas: UNICAMP, 2001.

p. $91-122$.

CALIL, Saide Jorge; TEIXEIRA, Marilda Sólon. Gerenciamento de manutenção de equipamentos hospitalares. São Paulo: Faculdade de Saúde Pública da Universidade de São Paulo, 1998. 108 p. (Série Saúde \& Cidadania, 11). 
CASTELAR, Rosa Maria; IWERSEN, Marcelo. O atual quadro sanitário do Brasil. In: CASTELAR, Rosa Maria; MORDELET, Patrick; GRABOIS, Victor. Gestão hospitalar: um desafio para o hospital brasileiro. Paris: ENSP, 1995. p. 29-37.

CHEVERIE, Joan F. The changing economics of information, technological development, and copyright protection: what are the consequences for the public domain? The Journal of Academic Librarianship, v. 28, n. 5, p. 325-331, sep./oct. 2002.

CUNHA, Murilo Bastos da. Desafios na construção de uma biblioteca digital. Ciência da Informação, Brasília, v. 28, n. 3, p. 257-268, set./dez, 1999.

DENNIS, Nancy K. Technology infrastructure supporting digital library developments. In: REENEN, Johann Van (Ed). Digital libraries and virtual workplaces important initiatives for Latin America in the information age. USA: IACD, 2001. p.157-165.

DRABENSTOTT, Karen; BURMAN, Celeste M. Revisão analítica da biblioteca do futuro. Ciência da Informação, Brasília, v. 26, n. 2, maio/ago. 1997. Disponível em: $<$ http://www.ibict.br>. Acesso em: 30 jan. 2004.

FERNÁNDEZ-MOLINA, Juan Carlos. Protección tecnológica y contractual de las obras con derecho de autor: hacia una privatización del acceso a la información? Ciência da Informação, Brasília, v. 32, n. 2, p. 54-63, maio/ago. 2003.

FERREIRA, Sueli Mara S. P. Design de biblioteca virtual centrado no usuário: a abordagem do Sense-Making para estudos de necessidades e procedimentos de busca e uso da informação. Ciência da Informação, Brasília, v. 26, n. 2, maio/ago. 1997. Disponível em: <http://www.ibict.br>. Acesso em: 30 jan. 2004.

GRUPO DE TRABALHO SOBRE BIBLIOTECAS VIRTUAIS DO COMITÊ GESTOR DA INTERNET-BRASIL (1997) Orientações estratégicas para a implementação de bibliotecas virtuais no Brasil. Ciência da Informação, Brasília, v. 26, n.2, maio/ago. 1997. Disponível em: <http://www.ibict.br>. Acesso em: 30 jan. 2004.

GUEIROS JÚNIOR, Nehemias. A ausência de territorialidade na internet. 2004. Disponível em: $\quad<$ http://www.mundojuridico.adv.br/html/colunista/nehemias01.htm>. Acesso em: 27 fev. 2004.

MARTINS FILHO, Plínio. Direitos autorais na internet. Ciência da Informação, Brasília, v. 27, n. 2, p.183-188, maio/ago. 1998.

MICHEL, Jean. Direito de autor, direito de cópia e direito à informação: o ponto de vista e a ação das associações de profissionais da informação e da documentação. Ciência da Informação, Brasília, v. 26, n. 2, p.140-145, maio/ago. 1997.

MODESTO, Fernando. Software livre: alforria para as bibliotecas. Coluna Tecnologia da Informação, Site OFAJ, nov./dez. 2003. Disponível em: <http://www.ofaj.com.br>. Acesso em: 27 jan. 2004. 
PEREIRA, Maria de Nazaré Freitas. Bibliotecas virtuais: realidade, possibilidade ou alvo de sonho. Ciência da Informação, Brasília, v. 24, n.1. 1995. Disponível em: $<$ http://www.ibict.br>. Acesso em: 30 jan. 2004.

VERGUEIRO, Waldomiro de Castro Santos. Desenvolvimento de coleções. São Paulo: Polis; APB, 1989. (Palavras-chave, 1). 96 p.

\section{Rosana Evangelista}

Mestre em Biblioteconomia - PUC-Campinas. Bibliotecária da Faculdade de Ciências Médicas da UNICAMP.rosanae@fcm.unicamp.br

\section{Vanda de Fátima Fulgêncio de Oliveira}

Graduada em Ciências Sociais e Biblioteconomia - PUC-Campinas. Bibliotecária do Centro de Atenção Integral à Saúde da Mulher (CAISM) da UNICAMP. vanda@unicamp.br

\section{Sandra Lúcia Pereira}

Mestre em Biblioteconomia - PUC-Campinas. Bibliotecária da Faculdade de Ciências Médicas da UNICAMP. sandralu@fcm.unicamp.br

\section{Valdinéa Sonia Petinari}

Graduada em Tecnologia em Processamento de Dados - UNISAL. Graduanda em Ciência da Informação com Habilitação em Biblioteconomia - PUC-Campinas. Especializanda em Gerência de Sistemas e Serviços de Informação. Responsável pela Central de Referência em Equipamentos Biomédicos do CEB/UNICAMP. val@ceb.unicamp.br

Artigo aceito para publicação em: 12/2004 